\title{
Territorios de agua: infraestructura agrícola, reforma agraria y palma de aceite en el municipio de Marialabaja (Bolívar)
}

Territories of Water: Agricultural Infrastructure, Agrarian Reform,
and Palm Oil in The Marialabaja Municipality, Bolivar

\author{
Catalina Quiroga Manrique* \\ Universidad de los Andes, Colombia \\ Diana Vallejo Bernal ${ }^{* *}$ \\ Universidad de los Andes, Colombia
}

DOI: https://doi.org/10.22380/2539472X.570

\begin{abstract}
RESUMEN
Las dinámicas de despojo y acaparamiento de agua son un eje central en investigaciones recientes que reconocen las relaciones asimétricas de poder y el poder de la naturaleza misma en el manejo, uso y control de los recursos. Sin embargo, no son muchos los trabajos sobre las alternativas de gestión local del agua. Este artículo aporta a este conjunto de literatura a partir de un acercamiento etnográfico al distrito de riego de Marialabaja (Bolívar), en el Caribe colombiano. El análisis de la construcción de esta obra ayuda a entender cómo la infraestructura se apropia como parte del territorio, a la vez que genera relaciones desiguales de acceso al agua. También muestra las consecuencias directas de una política de desarrollo rural en las vidas cotidianas de las poblaciones locales.
\end{abstract}

Palabras clave: agua, infraestructura, territorio, Marialabaja, Colombia.

\begin{abstract}
$\overline{\text { ABSTRACT }}$
Water grabbing and water dispossession have gained increasing attention in recent years. Contemporary approaches recognize asymmetrical power relations and the power of nature as central axes in resource management, use and control. However, there are few studies on local water management alternatives. This article seeks to contribute to this literature, from an ethnographic approach to the irrigation district of Marialabaja-Bolivar, in the Colombian Caribbean. This analysis helps to understand how infrastructure is appropriated as part of the territory as it also generates unequal water access relations. It also reveals the direct consequences of rural development policy in the everyday lives of local populations.
\end{abstract}

Keywords: water, infrastructure, territory, Marialabaja, Colombia.

\footnotetext{
* $\quad$ Magíster en Geografía de la Universidad de los Andes. Antropóloga de la Universidad Nacional de Colombia. catalina.qm@gmail.com.

** Antropóloga de la Pontificia Universidad Javeriana (PUJ) y candidata a magíster en Geografía de la Universidad de los Andes. dvallejo@javeriana.edu.co.
} 


\section{Introducción}

Desde tiempos históricos, el territorio de los Montes de María ha sido adornado por interminables arroyos que bañan sus campos y con ellos la producción diversificada de alimentos. Los diferentes mecanismos de acceso al agua han contribuido a la construcción del tejido social como pilar fundamental de la resistencia dentro del mismo territorio. Las maravillosas historias que giraban en torno a los pozos artesanales hacen de este, nuestro hogar, un espacio de discusión en torno a la vida misma de nuestras comunidades; alrededor del agua arreglábamos nuestros problemas y planeábamos nuestro futuro. (Duván Caro, joven campesino de la vereda Paloaltico. Fragmento Cartilla historia del distrito de riego)

l municipio de Marialabaja se ubica al norte del departamento de Bolívar en la región caribe colombiana, y en sus inmediaciones se encuentra el distrito de riego del mismo nombre. Allí, cientos de familias de la alta y media montaña de los Montes de María recorren distancias de hasta $2 \mathrm{~km}$ en busca de agua potable. El distrito de riego de Marialabaja cuenta con tres grandes lagos artificiales y un sinnúmero de canales de riego ${ }^{1}$ que ocupan más de 25.000 ha, y se conecta con un sistema cenagoso y el canal del Dique. En contraste con tal riqueza hídrica, solo el 18,2\% de los habitantes tiene servicio de acueducto y el 0,5\%, de alcantarillado (DANE 2005). Estos servicios funcionan con el agua del distrito y su cobertura se limita a la cabecera municipal, lo que obliga a los habitantes del área rural a emplear alternativas como la captación de agua lluvia o la recolección de agua en jagüeyes, pozos comunales o el distrito; fuentes hídricas contaminadas que no reciben ningún tipo de tratamiento, a diferencia del agua que se suministra a través del acueducto.

Este artículo busca entender las dinámicas de privatización, acaparamiento y despojo de agua a la luz de la historia de la infraestructura del distrito de riego de Marialabaja, construido en el marco de la reforma agraria de 1961. Proponemos nuestro análisis desde una perspectiva etnográfica ${ }^{2}$ y espacial; es

1 Los lagos artificiales y responden a los siguientes nombres: Arroyo Hondo o Playón, Matuya y Pondaje el Viento o La Piscina.

2 Este artículo recoge parte de los resultados de nuestras investigaciones en Montes de María (2014-2017), principalmente en el municipio de Marialabaja. Las investigaciones se realizaron 
decir, como un proceso de construcción del espacio en donde el Estado ${ }^{3}$ desempeña un papel importante en la definición, organización y regulación de este, mediante planes y programas que son objeto de disputas y tensiones (Lefebvre [1974] 2013, 83). La llegada del distrito no se agota en una simple cimentación; antes bien, debe ser abordada como un proceso constante en el que se sedimentan y acumulan entramados históricos, produciendo espacios de violencia y exclusión que se actualizan en las dinámicas del día a día (Ojeda 2016; Ojeda et al. 2015).

Abordar el distrito de riego desde esta perspectiva permite preguntarse por las maneras en las que se disputan el uso, acceso, control y distribución de los recursos y su relación con dinámicas de desigualdad y violencia. En esa medida, se reconocen los enfrentamientos entre fuerzas antagónicas posicionadas de manera desigual. Aun así, desde fuerzas distintas al Estado y al capital —al desarrollo (Harvey 2005) 4 -, surgen iniciativas locales de ordenamiento ambiental del territorio que resquebrajan las lógicas oficiales sobre la propiedad y el acceso a la naturaleza, particularmente al agua, y se constituyen en ejercicios de defensa del territorio (Quiroga 2016; Vallejo 2016). Partiendo de lo anterior, el objetivo principal del artículo es analizar los escenarios de resignificación del territorio asociados al agua y al distrito de riego por parte de las organizaciones de base rural de Marialabaja.

Entendemos la resignificación como un proceso en el cual las poblaciones locales construyen nuevos significados sobre la infraestructura a partir de sus prácticas cotidianas, que a su vez entran en tensión con los significados producidos por las instituciones competentes y los empresarios, sin anularse entre ellos. Queremos enfatizar las transformaciones semánticas que resultan de la puesta en práctica de formas diferentes a la producción capitalista de usar el agua y la infraestructura del distrito de riego; es decir, formas distintas de reproducir la vida y construir el territorio (Gutiérrez y Salazar 2015). Un ejemplo de ello es la

a partir de recorridos etnográficos, entrevistas semiestructuradas, observación participante y revisión de archivo. De igual manera, es importante señalar que estos trabajos buscan crear espacios de investigación colaborativa, rescatando la importancia de las voces locales y de producir conocimientos con y para la gente. Bajo este principio, el proceso de investigación logró la creación conjunta de documentos sobre historia local, con la participación de pobladores rurales vinculados a organizaciones de base (véase Aguirre et al. 2016).

3 Nos referimos al Estado como un hecho social compuesto por instituciones, políticas públicas y construcciones ideológicas (Abrams [1977] 2015), y no como una idea dada, homogénea y totalmente articulada. En esa medida lo entendemos como "estado", atendiendo a la propuesta de desreificar el concepto. Véase también Mitchell ([1999] 2015). Sin embargo, respetando las normas de la RAE, en este artículo se escribirá con mayúscula.

4 Harvey enriquece los planteamientos de Lefebvre en la medida en que tiene en cuenta la acumulación del capital (el cual requiere de un constante despojo) en el proceso de construcción del espacio. 
instalación de carteles sobre el cuidado ambiental de la laguna en las inmediaciones de lo que fuera construido como una represa, cuyo objetivo es suministrar agua a grandes extensiones de cultivos. Mientras que los jóvenes defienden un bien común, la institucionalidad controla y comercializa una mercancía susceptible de ser privatizada.

Todos estos procesos que dotan de sentido al agua y a la infraestructura se pueden reconocer en la historia del distrito de riego de Marialabaja. El distrito fue resultado de la Ley de Reforma Social y Agraria ${ }^{5}$ de 1961, con el propósito de proveer riego continuo para cultivos permanentes como el arroz. Sin embargo, en 1990 se produjo un declive arrocero a causa de las importaciones del producto fomentadas por la apertura económica. En esta misma década, durante la presidencia de Andrés Pastrana (1998-2002), se afianzó la producción agroindustrial en la región mediante el incentivo al cultivo de palma de aceite. La llegada y consolidación de la palma estuvo acompañada por el recrudecimiento del conflicto armado y la presencia paramilitar en la zona. Como resultado de lo anterior, el distrito de riego se ha convertido en el centro de las disputas entre el Estado, los empresarios palmeros y los pobladores locales; mientras que los primeros lo posicionan como un recurso para la producción, las poblaciones locales lo reclaman como la fuente de vida y sustento que hace parte de su territorio. Significados distintos que atraviesan las dinámicas del ciclo de privatización/acaparamiento/ despojo de tierra y agua en el municipio, materializado en la transferencia de la administración a una entidad privada centrada en el control de suministros, en el uso exclusivo del agua para los cultivos de palma y en la imposibilidad de las poblaciones rurales de acceder al agua, como lo hacían antes de la construcción del distrito de riego. Son formas de despojo que transitan entre la imposición de la violencia y la creación de leyes, y que resultan en situaciones como la instalación de cercas y la vigilancia paramilitar alrededor de los cultivos de palma que impiden la movilidad de las poblaciones sin tierra y el acceso a ojos de agua que solían usar.

El proceso de investigación partió de la ecología política, campo multidisciplinar que ofrece herramientas para el análisis de los conflictos derivados de las formas de acceso y control de los recursos, teniendo en cuenta su dimensión política y ecológica. Este campo busca entender el papel de los diferentes actores - Estado, poblaciones locales, empresas, entre otros- en dichas formas de

5 La Ley 135 de 1961 de Reforma Agraria fue una iniciativa del presidente liberal Carlos Lleras Restrepo para prevenir la inequitativa concentración de la propiedad rural, luego de la instalación del Frente Nacional. La norma buscó facilitar el acceso a la propiedad de las poblaciones del campo en relación con la promoción de espacios de conservación y de uso común. 
acceso y control, así como las características ecológicas de la naturaleza. Parte de la premisa de que la naturaleza es producida socialmente y de que su producción está estrechamente vinculada a las dinámicas socioeconómicas, culturales, políticas e institucionales (Coronado y Dietz 2013, 98). El análisis del distrito de riego nos permitió reconocer la multidimensionalidad de las desigualdades y las interdependencias entre lo local, nacional, transnacional y global (Göbel, Góngora-Mera y Ulloa 2014), un elemento fundamental en la comprensión de los flujos de poder relacionados con procesos de despojo, defensa y resignificación del territorio en el municipio de Marialabaja.

En la actualidad, encontramos una producción académica robusta sobre problemas asociados al agua, que parten de entender la relación entre sociedad y naturaleza como un proceso de coproducción. En ese sentido, se cuestiona la idea de una única naturaleza existente de antemano y se opta por entenderla en su pluralidad de significados, adscritos a procesos constantes de producción, en contextos concretos, con dinámicas políticas, sociales y económicas específicas. Algunos ejemplos son los trabajos enfocados en el análisis de procesos de neoliberalización de la naturaleza asociados al agua (Bakker 2015; Prudham 2004); los estudios sobre privatización y escasez de agua (Mehta 2007; Perrault 2014); las experiencias de sufrimiento generadas por la escasez y contaminación desde una perspectiva de género (Sultana 2011), y el análisis de tecnologías que median la relación con el agua (Barnes 2012; Carse 2012), entre otros. En Colombia, se resaltan propuestas como las de Camargo (2008) y su análisis sobre el papel del Estado en la gestión de los recursos hídricos; Vélez-Torres (2012), sobre el despojo de agua en relación con procesos de etnización y racialización ambiental, y López (2013) sobre el acceso desigual al agua en sectores urbanos, como consecuencia de reformas económicas neoliberales. Este artículo busca contribuir a esta literatura a partir del análisis de las dinámicas de acaparamiento y despojo de agua, asociadas a proyectos de desarrollo impulsados por el Estado en el Caribe, destacando las estrategias locales de defensa del territorio y los significados en disputa sobre la naturaleza.

Por esta razón, la relación de coproducción entre sociedad y naturaleza se analiza a través del papel activo del agua, entendida como un recurso socionatural (Bakker 2003; Budds 2010). El agua es un recurso cuya materialidad es tan importante como los significados que se tejen sobre ella; su flujo se media social y discursivamente y encarna distintos significados para la gente (Budds 2010, 40). El agua es un recurso activo que, junto con la sociedad, se construye y reconstruye en el tiempo y en el espacio (Linton y Budds 2013) y establece relaciones dialécticas atravesadas por objetos sociotécnicos (Bakker 2012). Siguiendo esta idea, el distrito de riego como proyecto de infraestructura agrícola es una huella en 
el territorio que media la relación entre agua y sociedad, al tiempo que modifica y genera formas de poder que derivan del control hídrico (Swyngedouw 1999).

Desde este enfoque, el agua se configura como un elemento central en los procesos de defensa territorial, pues tanto para campesinos y organizaciones sociales como para palmicultores y ganaderos, adquiere distintos significados que coinciden y chocan en su ingente necesidad. Las organizaciones sociales de la región sustentan parte de sus reivindicaciones en la inclusión del distrito de riego dentro de su delimitación del territorio campesino porque el agua es el centro de la organización de su territorio. Palmicultores y ganaderos encuentran en el distrito la fuente principal de abastecimiento para el mantenimiento de plantaciones y pastos; es fundamental para la generación de capital. En ese sentido, la definición de subjetividades locales, que va de la mano de un ejercicio de delimitación de los espacios, se relaciona con la producción de relaciones sociales, económicas y culturales alrededor de los cuerpos de agua de la zona, teniendo en cuenta sus ciclos y los espacios de producción y conservación.

Haciendo énfasis en el territorio como una categoría central en la disputa local, lo entendemos como la construcción sociofísica de las representaciones y narrativas del espacio habitado, sus usos, problemas, delimitaciones y transformaciones en medio de dinámicas históricas de poder y significados sociales (Fernandes 2010; Harvey 2005). El territorio abarca tanto el espacio físico como los vínculos que se establecen con este, facilita la comprensión de las luchas simbólicas que se tejen entre distintos actores y legitima las formas de apropiación espacial, enmarcadas en una serie de relaciones de poder que disputan dicha legitimidad (Cortés, Quintero y Valcuende 2008). Alrededor del distrito identificamos la configuración de un territorio de agua en el que se integran la dimensión social, política y natural, abriendo paso a un proceso constante de construcción y significación, a partir de la interacción entre prácticas humanas, flujos de agua, elementos biofísicos, tecnologías hidráulicas, estructuras económicas e instituciones políticas; elementos que se posicionan de manera desigual y tienen efectos en diferentes escalas (Boelens et al. 2016).

Nuestra investigación etnográfica comprende el análisis de distintas dimensiones (multiescalar, multitemporal, multisituado y multiagente) en el estudio de conflictos socioambientales (Del Cairo, Montenegro y Vélez 2014). Por multiescalar entendemos la interdependencia de escalas de acción política en relación con el problema del agua. En este caso, la producción de palma de aceite y las políticas implementadas en la región responden a una serie de lineamientos mundiales que privilegian una forma particular de comprender el agua. En relación con la dimensión de multiagente, identificamos que en Marialabaja cada 
una de estas escalas en tensión está construida socialmente por un actor que ordena el territorio y disputa sus significados sobre la naturaleza. Los actores en este trabajo son campesinos, organizaciones sociales, funcionarios del Estado y palmicultores; entonces, por multitemporal nos referimos a la importancia de reconocer la historia contada por varias voces. Finalmente, abordamos la dimensión multisituada como las rupturas y continuidades en la producción de las tensiones por el significado del agua en Marialabaja, mediante el análisis de las transformaciones en las formas de acceso al agua y la producción de los sentidos a causa de estas transformaciones.

Para el desarrollo de nuestro objetivo, el artículo se ha organizado en cuatro apartados. El primero presenta a las personas que viven en la región y describe el funcionamiento del distrito de riego, así como los elementos de contexto y sus condiciones biofísicas. En segundo lugar, se explica el proceso de construcción del distrito de riego a varias voces y los efectos locales de la implementación de la Ley 135 de 1961. Si bien no es un ejercicio historiográfico, se resalta la importancia de la perspectiva histórica en el examen de las disputas actuales alrededor del agua en Marialabaja. El tercer apartado analiza la relación entre las políticas de apertura económica de la década de los noventa y la llegada de la palma de aceite al municipio, mostrando cómo las apuestas de desarrollo estatales favorecieron el acaparamiento de recursos estratégicos por actores empresariales y despojaron a las poblaciones locales de estos. El último apartado se centra en la manera en que estas dinámicas se encarnan en la cotidianidad de las personas y cómo desde allí surgen alternativas para hacer frente al despojo de agua. Se destacan las prácticas locales de resignificación del distrito de riego y el agua como base de los procesos de defensa del territorio y la reproducción de la vida en común.

\section{El distrito de riego de Marialabaja y su gente}

El distrito brinda agua para riego a 2.035 familias que se ubican en un área total de 18.390 ha (Incoder 2015) ${ }^{6}$. De los tres municipios que hacen parte del área de beneficio, Marialabaja tiene un $75 \%$ del total de la superficie del sistema, Arjona

6 En entrevistas realizadas en el 2015, funcionarios del Instituto Colombiano de Desarrollo Rural (Incoder) mencionaron que el distrito es uno de los más importantes en el país y funciona gracias a la inversión del sector palmero. 
cuenta con un $15 \%$ y Mahates con un $10 \%$ (Incoder 2008). El distrito, incluyendo las represas y los sistemas de captación de agua de los arroyos de alta montaña, ocupa un área de 25.000 ha, la mitad del total de la superficie del municipio de Marialabaja. Además de la infraestructura para la distribución y el manejo del agua, la obra cuenta con vías carreteables paralelas a los canales que facilitan la comunicación entre corregimientos y veredas (véase figura 1).

La administración del distrito depende de una entidad privada sin ánimo de lucro nominada Usomarialabaja, que actúa bajo supervisión del Incoder. Si bien el distrito es propiedad del Estado, Usomarialabaja se encarga de su administración gracias a la figura de concesión. Según Alfonso Torres ${ }^{7}$, gerente de la entidad en el 2014, a esta le corresponde la selección del personal administrativo a través de la asamblea general, cuyos miembros son dueños de tierras cultivadas con palma y algunos arroceros locales, pues un requisito para hacer parte de la asamblea es ser propietario legal de la tierra. Usomarialabaja también se encarga de los cobros y el control de la distribución del agua. Este hecho es importante para comprender las formas de relación entre las poblaciones locales sin tierra productiva con la infraestructura y con el Estado.

El distrito de riego funciona por gravedad: la parte más alta se ubica a $700 \mathrm{~m} \mathrm{s.} \mathrm{n.} \mathrm{m.} \mathrm{y} \mathrm{surte} \mathrm{de} \mathrm{agua} \mathrm{a} \mathrm{la} \mathrm{zona} \mathrm{baja} \mathrm{del} \mathrm{municipio} \mathrm{mediante} \mathrm{el} \mathrm{repre-}$ samiento de los arroyos Matuya y Arroyo Grande, que nacen de la parte alta de los Montes de María en los municipios de Carmen de Bolívar y San Jacinto. Sus aguas terminan en el complejo de ciénagas de Marialabaja y en el canal del Dique, que sirven de rebosadero en épocas de crecientes e inundaciones. Las formas de control de la distribución de agua se basan en un sistema de compuertas ubicadas en la represa Arroyo Hondo - la más grande e importante del distrito-. Desde allí, la administración controla los tiempos y las cantidades de agua que surten al canal principal. Tal como una llave de agua del hogar, las compuertas permiten la circulación del líquido entre los canales principales, los secundarios y la entrada del agua a cada finca. Abrir o cerrar esta llave es decisión de Usomarialabaja.

Las lógicas de provisión del agua del distrito están estrechamente ligadas con las condiciones climáticas de la región. Marialabaja, y en general Montes de María, tienen un clima seco tropical, con una temperatura que oscila entre los $24{ }^{\circ} \mathrm{C}$ y los $30^{\circ} \mathrm{C}$ (Aguilera 2013). Atendiendo a los patrones pluviales, el distrito realiza una campaña de riego anual en el primer semestre del año y deja el segundo semestre - la época de lluvia — para la recuperación de los embalses. De

7 En los dos últimos años, los gerentes de Usomarialabaja también han sido propietarios de tierras beneficiarias del riego. Por ejemplo, Alfonso Torres tiene 120 ha de cultivos de palma que emplean agua del distrito (A. Torres, comunicación personal, enero del 2015). 

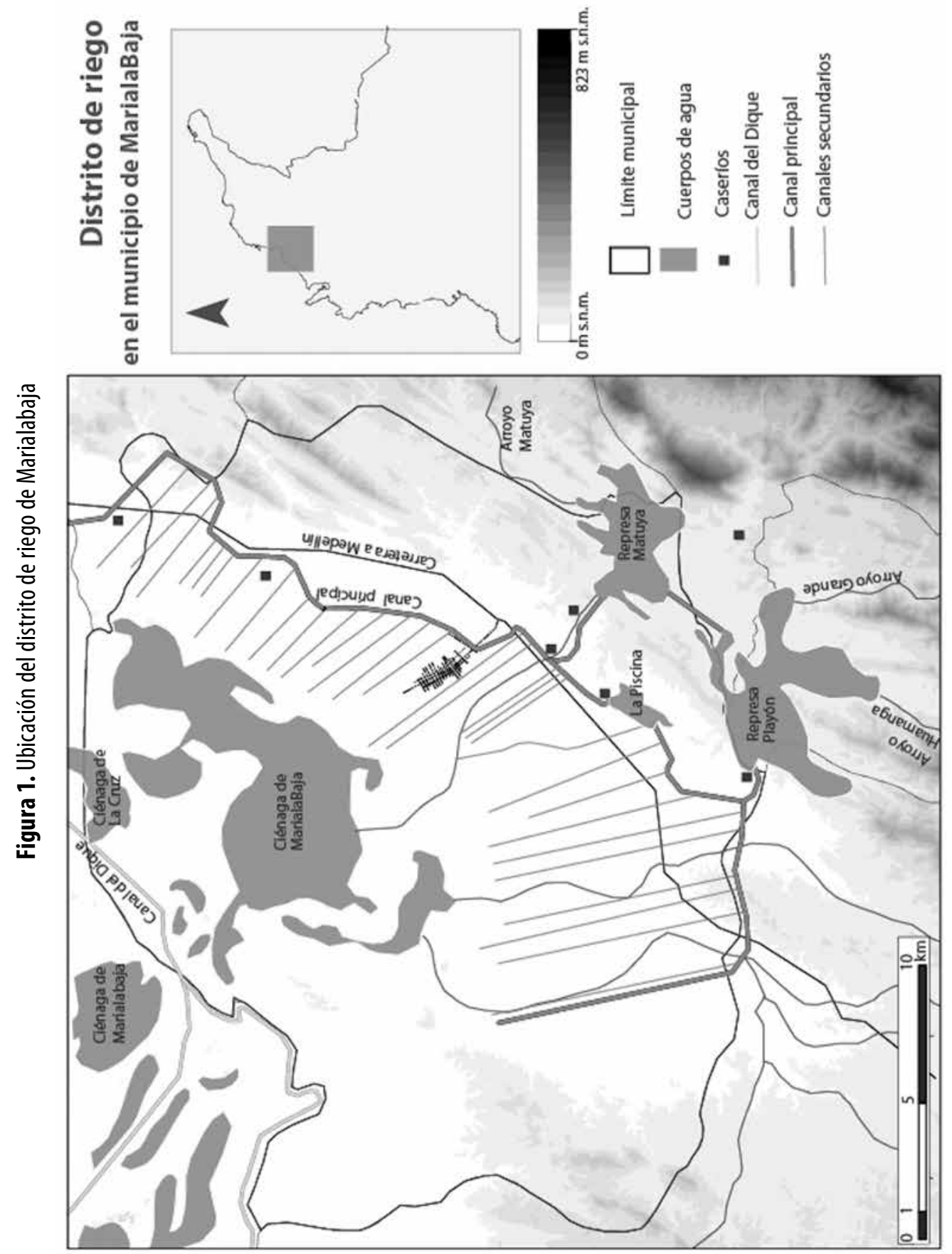
ello se sigue una relación entre los patrones climáticos, las temporadas de riego y las lógicas de producción, pues las zonas bajas se benefician con agua durante todo el año, ya sea de lluvia, del distrito o de las ciénagas. En contraste, las zonas medias y altas solo cuentan con la temporada de lluvias para la siembra. El distrito de riego y la disponibilidad de agua modifican las prácticas cotidianas dependiendo del lugar donde se ubiquen las poblaciones, de allí que cada comunidad le dé un significado diferente al agua de acuerdo con su uso.

Del mismo modo, la delimitación de zonas según la altura está ligada a la cadena montañosa que atraviesa la región, conocida como Serranía de San Jacinto, que condiciona las formas de tenencia, el área de los predios y las formas de propiedad. Se reconocen tres: la zona de montaña o zona alta, con el menor número de habitantes, en su mayoría pequeños propietarios sin títulos; la zona de piedemonte o zona media, con la mayoría de población concentrada en caseríos, que basa su sustento en el trabajo en las grandes plantaciones de palma, y la zona Troncal Río Magdalena o zona baja, que tiene una mayor densidad poblacional y se caracteriza por sus grandes extensiones de plantaciones de palma de aceite, pastos y arroz, así como por las industrias de procesamiento del aceite de palma y el casco urbano del municipio.

Lejos de ser una infraestructura ajena e intocable con una serie de restricciones para quienes no pagan por el riego, el distrito es un espacio en disputa en medio de los procesos de movilización por un territorio campesino y étnico. El agua es parte importante en las discusiones sobre el ordenamiento local y, en últimas, sobre las políticas de desarrollo de la zona. Al respecto, un campesino local menciona: "ya perdimos la tierra, ahora tenemos que luchar por el agua". En consecuencia, las poblaciones rurales que se ubican en las inmediaciones del distrito adelantan procesos de reconocimiento étnico, cultural y territorial, como los consejos comunitarios afrocolombianos, los cabildos indígenas zenúes y las zonas de reserva campesina ${ }^{8}$. Para todas las organizaciones que impulsan

En el año 2010 el presidente Juan Manuel Santos (2010-2014) y el Incoder plantearon la creación de una zona de reserva campesina en la región de Montes de María. La propuesta se recibió con desconfianza porque provino del Gobierno nacional y generó tensiones entre grupos étnicos, asociaciones de víctimas y organizaciones campesinas. Con el fin de superar dichas tensiones, las organizaciones sociales presentes en la región vienen promoviendo espacios de discusión y concertación, tanto con el Gobierno nacional como con los cabildos indígenas, los consejos comunitarios y las comunidades campesinas, para lograr acuerdos territoriales que garanticen, por un lado, el pleno cumplimiento de los procesos de titulación colectiva para grupos étnicos y víctimas del conflicto y, por otro lado, que contribuyan a proteger el territorio. Ejemplo de ello fue la contrapropuesta de campesinos, indígenas y afrodescendientes de crear una zona intercultural de protección territorial para proteger el territorio de la expansión de monocultivos, como la palma y la teca, y al tiempo promover la "agricultura familiar". Esta propuesta sigue en construcción. 
estos procesos el distrito de riego es la fuente de agua más importante que permite la reproducción de la vida.

Las voces que sustentan este trabajo son de campesinos y campesinas cuyas familias se encontraban allí antes de la construcción del distrito de riego; otros llegaron como consecuencia del desplazamiento que significó la construcción de este, como es el caso de Paloaltico, y otros buscaron trabajo en la zona y se instalaron allí, como en el caso de La Suprema. Estas voces locales se refieren a líderes de la Organización de Población Desplazada, Étnica y Campesina de los Montes de María (OPDS), de escala regional; miembros de organizaciones veredales de San José de Playón, Paloaltico y La Suprema, adscritas a OPDS, y algunos habitantes locales de dichos lugares. La mayoría de estas familias hacen parte de los 1.042 propietarios que poseen menos de 1 ha de tierra ${ }^{9}$ (Incoder 2012).

\section{Reforma agraria, construcción del distrito de riego y arroz}

A finales del siglo XIX, el gobierno de Rafael Reyes otorgó un incentivo para la construcción de un ingenio azucarero en la zona baja de Montes de María (Ripoll de Lemaitre 1997, 66) a los hermanos Carlos y Fernando Vélez Daníes, empresarios ganaderos de la sociedad cartagenera. El incentivo buscaba contener la producción bovina de la región, a causa de la sobreproducción de carne para el consumo interno (Ripoll de Lemaitre 1997, 65). Con dicho apoyo, los hermanos Vélez construyeron el ingenio Sincerín, la primera iniciativa de producción azucarera en el país. Su ubicación le permitió el beneficio de la alta fertilidad de los suelos por cuenta de la cercanía al sistema cenagoso de Marialabaja y el Canal del Dique.

El área calculada del ingenio era de 50.000 ha ubicadas entre los municipios de Mahates, Arjona y Turbaco. Su funcionamiento se basó en la adecuación de lotes de 50 ha asignados a colonos, quienes se encargaban de contratar los jornales de siembra, corte y limpieza (Ripoll de Lemaitre 1997). De la mano de la producción de azúcar, la ganadería continuó como actividad importante en la

9 Según la caracterización realizada para la formulación del Plan de Desarrollo Sostenible de la Zona de Reserva Campesina en Montes de María, la relación entre el número de habitantes y las hectáreas de tierra es la siguiente: menos de 1 ha, 1.042 propietarios (0,5\%); entre 1 y 20 ha, 2.583 propietarios (26,8\%); entre 20 y 500 ha, 754 propietarios (52,6\%), y entre 500 o más hectáreas, 6 propietarios $(20,1 \%)$. 
región, ocasionando un cambio notorio en el paisaje por la transformación del bosque seco en potreros para el ganado (Van Ausdal 2009). Dicha transformación fue importante en la ampliación de la frontera agrícola y las relaciones de patronazgo que se establecieron entre colonos, campesinos, indígenas, comunidades negras y los empresarios del azúcar. Al tiempo que el ingenio proveía de trabajo, vivienda y salud a sus jornaleros (Ripoll de Lemaitre 1997), otros habitantes se desplazaban hacia las zonas altas en busca de tierra para la habitación y la siembra de cultivos de pancoger.

Durante este periodo, el acceso al agua era libre para las poblaciones rurales, los ganaderos y el ingenio, ya que se disponía de los arroyos y escorrentías de la zona alta, las ciénagas, pozos y jagüeyes de las zonas medias y bajas y las lluvias. Si bien los habitantes locales no tenían dificultades para acceder al líquido, los productores de caña y el Estado concebían el agua como un obstáculo para el aprovechamiento real de los suelos (Camargo 2008). Ejemplo de ello fueron los esfuerzos de ampliación de la frontera agrícola, no solo por medio de la ganadería (Fals 1976), sino a través de prácticas de dragado y desecamiento de cuerpos de agua como las ciénagas y el canal del Dique (García 2014).

Con la crisis económica de 1929, los precios del azúcar se vieron afectados drásticamente; para entonces los ingenios azucareros del Valle del Cauca habían cobrado protagonismo a escala nacional. Aunque la crisis afectó la producción azucarera de todo el país, el ingenio Sincerín no logró recuperarse; su producción era inferior a la de otros ingenios y nunca alcanzó una producción de dos zafras ${ }^{10}$ anuales por la falta de un sistema de riego continuo que controlara el flujo hídrico (Ripoll de Lemaitre 1997). La dependencia de los regímenes pluviales propició prácticas de trashumancia y movilización de animales y cultivos hacia las zonas medias (Herrera 2002) en época de lluvia y situaciones de escasez de agua durante el verano.

Estos hechos contribuyeron a la disolución del ingenio en 1950. En los años siguientes, la ganadería extensiva recobró importancia en la región y abonó el terreno para la concentración de la propiedad en las zonas planas del municipio, hecho que motivó la implementación de la reforma agraria en la zona y la construcción de la infraestructura agrícola. El distrito de riego debe ser entendido como parte del proceso de consolidación de los monocultivos fomentados por las políticas de desarrollo del país. Al respecto, un campesino de Mahates menciona:

Bueno, lo primero es remontarnos un poco a inicios del siglo pasado, por allá en 1910 exactamente entra todo lo que es el capitalismo salvaje a la

10 Mientras que en el Valle del Cauca se daban dos zafras anuales, en el Caribe se daba solo una; esta producción estaba relacionada directamente con la provisión de agua. 
costa, a esta zona. Prácticamente por esta parte del país - y eso entra aquí a Sincerín - con un ingenio azucarero, el primero y el más grande de Latinoamérica. En ese entonces se llamó la Compañía Azucarera Colombiana, eso después era de capital de los gringos, ellos la llamaban Colombian Sugar Company [...] entonces esto tenía ese gran capital extranjero y estas tierras eran de los hermanos Vélez Daníes. (Leonardo ${ }^{11}$, Mahates, junio del 2014)

El distrito de riego fue construido por el Instituto Colombiano de Reforma Agraria (Incora), en la década de los sesenta, con la intención de adecuar tierras fértiles y brindar tierras a campesinos pobres para la producción de alimentos durante todo el año, garantizando riego continuo a partir del control de agua. El $45 \%$ del costo de la primera etapa de obras (equivalente a 5,2 millones de dólares) fue financiado por el Banco Interamericano de Desarrollo en el marco de la Alianza para el Progreso. El valor restante, equivalente a 6,3 millones de dólares, fue asumido por el Incora (Incora 1968). La distribución del suelo en la zona en el momento de la construcción del distrito era la siguiente: 1.500 ha para caña, 5.000 ha para plátano, 10.000 ha de pastos para la ganadería y las restantes 3.500 ha para cultivos menores (yuca, maíz, ñame, frutales, aguacate, plátano, entre otros) destinados al consumo local (Caviedes 1975; Incora 1968). Si bien la diversificación del uso del suelo fue entendida como una ventaja para desarrollar un sistema de riego de gran escala, la concentración de la tierra representaba el mayor obstáculo de la construcción de la infraestructura y la implementación de la reforma agraria.

La construcción del distrito de riego demostró un afán por domesticar la naturaleza que había sido un gran obstáculo para la productividad de la tierra. El control de caudales fue también una apuesta institucional por controlar las relaciones de los habitantes locales con el agua y su entorno. La intervención sobre el flujo del agua a través de compuertas fue una de las principales técnicas de mediación de las relaciones de la gente con la naturaleza; el acceso ya no era libre y las personas debían solicitar permiso a la administración de la infraestructura para abrir las compuertas en épocas de sequías y cerrarlas durante las crecientes. Aun hoy estos permisos deben ser solicitados por los habitantes de la parte baja que viven a los costados de los canales sin una gota de agua.

La puesta en marcha de las políticas de desarrollo de la época y la construcción del distrito modificaron, por un lado, las formas de cultivo que se concentraron en la producción de arroz y, por otro, las formas de movilidad dentro 
de la zona. El uso de fertilizantes, la compra de semillas aprobadas por el Incora y la introducción de lanchas a motor para atravesar los cuerpos de agua del distrito fueron algunos de los cambios concretos en las relaciones de los habitantes con la naturaleza. Otro de los cambios que se vería reflejado en el desgaste del ciclo hídrico fue el uso de agroquímicos asociados a la Revolución Verde.

En resumen, queremos destacar que la presencia física del distrito de riego en el espacio es resultado de un conocimiento experto y de intereses económicos, privados y estatales. La sumatoria de dichas posturas se ve reflejada en la distribución desigual de los servicios que la infraestructura provee, posibilitando el acceso para unos y excluyendo de su beneficio a otros (Carse 2012). Es decir, la infraestructura no es un simple artificio separado de la naturaleza; su irrupción en el paisaje genera nuevas relaciones entre la gente y su entorno, nuevos modelos de producción y apropiación del espacio en los que se termina por asumir la obra como parte de la naturaleza (Carse 2012). Lo anterior se observa en las percepciones de un exfuncionario del Incora que trabajó en el distrito después de 1975:

El Incora manejaba todo, absolutamente todo. Desde el acceso a la tierra, suministrarle a la gente pues, digamos, todo lo referente a la organización, al empoderamiento organizacional, capacitación, asistencia técnica; éramos banco, prestábamos plata también. El Incora en su momento construía infraestructura física como esa, infraestructura social, que de todas maneras, en muchos departamentos como Arauca, como en el Putumayo, prácticamente todas esas poblaciones nacen a raíz de la presencia del instituto. (Exfuncionario del Incora, junio del 2015)

El funcionamiento del distrito segregó automáticamente a los habitantes de las zonas medias y altas, privándolos del beneficio de riego, al tiempo que aseguraba agua constante para las parcelas y fincas ubicadas en las zonas bajas. Aunque en principio la implementación de la Ley 135 de 1961 buscaba contrarrestar la alta concentración de la tierra a partir de la imposición de una unidad agrícola familiar ${ }^{12}$ (UAF), el efecto fue contrario para algunas poblaciones locales. En esta región, se estipuló el tamaño de una UAF de 10 ha en las zonas bajas y 20 ha en las zonas medias y altas, y con la instalación del distrito de riego, el $90 \%$ del área de las parcelas debía destinarse al cultivo de arroz asistido por riego, dejando el $10 \%$ restante para cultivos de autoconsumo. Puesto que el arroz era

12 Según la ley, la UAF era una extensión de tierra suficiente para el sostenimiento de una familia y cuyo manejo no requiriera mano de obra adicional a la del núcleo familiar. Lo que se obtuviera de ella debía ser suficiente para garantizar el autoabastecimiento y el pago del crédito adquirido en el proceso de parcelación (capítulo X, artículo 51). 
impuesto por la ley, los campesinos se vieron en la necesidad de adquirir obligaciones con la institucionalidad dispuesta para la implementación de la reforma - principalmente con la Caja Agraria ${ }^{13}$ - . La imposición de nuevas prácticas financieras, como los créditos bancarios y el manejo de chequeras, entre otros, reforzó la desconfianza de la gente hacia la reforma y los funcionarios del Incora, por lo que muchas familias optaron por abandonar sus parcelas e incluso se rehusaron a ser beneficiarios de la parcelación y la entrega de tierras que proponía la reforma.

Con los cambios de gobierno en los años setenta, los principios de la reforma agraria se modificaron (Albán 2011), al tiempo que el panorama nacional empezaba a convulsionar por cuenta del surgimiento y fortalecimiento de las guerrillas. Para la región de Montes de María, la presencia guerrillera fue concomitante con la acción de la Asociación Nacional de Usuarios Campesinos (ANUC) ${ }^{14}$, razón por la cual se fortaleció la percepción de la región como un nicho guerrillero que debía intervenirse ${ }^{15}$. Pese a un contexto agitado por las acciones del movimiento campesino y las guerrillas de las Fuerzas Armadas Revolucionarias de Colombia-Ejército del Pueblo (FARC-EP), el éxito de algunos arroceros atrajo la atención de actores externos que contaban con el capital suficiente para la compra de grandes extensiones de tierra, hecho que profundizó la concentración de esta.

Si bien hubo un periodo de bonanza arrocera, los grandes propietarios empezaron a sortear el robo de ganado por parte de la guerrilla — que para algunas personas estaba relacionada con el movimiento campesino-, lo que radicalizó las relaciones locales entre grandes ganaderos y campesinos organizados. La confluencia de estos factores, sumados al cambio de política económica nacional,

La Caja Agraria, creada por el Gobierno en 1931, fue la entidad bancaria estatal más importante del país encargada del fomento al campo. En la década de los sesenta tuvo el mayor número de empleados (16.500), la red de oficinas más numerosa (864) y actuó como único banco en cerca de 500 municipios, hecho que le permitió tener un récord de usuarios. La caja fue el mayor prestamista del campo durante 50 años. Su liquidación se inició el 26 de junio de 1999 y finalmente desapareció en el 2007 ("Caja Agraria: adiós a otra insignia nacional" 2007).

La ANUC fue una organización creada en 1967 (Decreto 755, en el marco de la Ley 135 de 1961), durante la presidencia de Carlos Lleras Restrepo, con el objetivo de fomentar la participación campesina en el proceso de reforma agraria. En sus primeros años logró trabajar de la mano con la Caja Agraria y el Incora y ejecutó algunas "tomas de tierra" en el territorio nacional. Debido a divisiones internas y al tinte "antirreforma" de los gobiernos posteriores, en 1972 la ANUC se dividió en la línea Armenia, más conservadora, y la línea Sincelejo, más radical. En la región de Montes de María hizo presencia la línea Sincelejo (Pérez 2010). 
causó el fracaso del arroz. En la década de los noventa, la apertura económica favoreció la creación de nuevas políticas para el sector agropecuario que apuntalaron la producción de monocultivos permanentes para la exportación. En Marialabaja se privilegió la producción de palma de aceite, teniendo la garantía del riego permanente del distrito.

\section{Palma de aceite, escalada paramilitar y neoliberalización de la naturaleza}

La década de los noventa inició con la presidencia de César Gaviria (1990-1994) y su política de apertura económica, sustentada en el principio de ventaja comparativa y la eliminación del modelo de industrialización por sustitución de importaciones (ISI) que había caracterizado las iniciativas agrarias en las cuatro décadas anteriores (Martínez 2006). Las nuevas políticas propiciaron la importación de arroz desde el Sudeste Asiático (Molano 2011) y significaron la quiebra total de los pequeños arroceros en Marialabaja, afectados por las deudas que dejó la Caja Agraria y el fortalecimiento de la ganadería como sistema productivo regional. El cambio en la estructura administrativa y la privatización del acceso al agua del distrito de riego también profundizaron la crisis.

La apertura económica se adscribe a un régimen al que algunos autores denominan neoliberalización de la naturaleza, en el que la extracción de recursos naturales funciona como vía de inserción a los mercados globales, generando tensiones y antagonismos frente al acceso, uso y distribución de estos en la escala local y beneficios económicos para sectores privados de orden global, lo que configura procesos sofisticados de acaparamiento y despojo de recursos (Alimonda 2011; Bakker 2015; Castree 2008; Harvey 2005). En Montes de María este proceso se caracterizó por la puesta en marcha de reformas basadas en dos elementos básicos del proyecto neoliberal: la privatización y la comercialización de la naturaleza. La privatización implicó un cambio en las relaciones de propiedad, es decir, se dio una transferencia del manejo público al control privado del distrito de riego. La comercialización ocurrió por cambios institucionales que modificaron las prácticas del manejo del agua convirtiéndola en una mercancía necesaria para la producción de aceite de palma. En resumen, el proceso de neoliberalización de la naturaleza se caracterizó por dotar de valor de cambio a los bienes comunes (Bakker 2010). 
La privatización del distrito de riego comenzó en el mes de junio de 1994, año en el que el Instituto Colombiano de Adecuación de Tierras (INAT) ${ }^{16}$ y la Asociación de Usuarios para el Distrito de Marialabaja —entonces llamada Asodimar-firmaron un contrato concesional en el que el Estado le cedía a la asociación la administración de la infraestructura sin perder la propiedad de esta. La transferencia implicó la responsabilidad del recaudo de tasas de agua, elaboración de presupuestos y planes de manejo por parte de Asodimar (Vermillion y Garcés 1999); sin embargo, la entrega real ocurrió a finales de 1996. La cesión de la administración del distrito de riego a las asociaciones de privados, que tenía como requisito incluir en la gestión de los recursos a los usuarios propietarios legales de tierras beneficiadas, tuvo varios problemas; el más importante fue la incapacidad de las asociaciones de garantizar su mantenimiento debido a los altos costos. Gran parte de los usuarios no contaban con el dinero para pagar el beneficio de riego ni las obligaciones contraídas con la Caja Agraria, como consecuencia del descalabro arrocero. Dada la informalidad de la tenencia de la tierra en la región y la cantidad de trabajadores del campo sin acceso a tierra, la Asociación de Usuarios estaba constituida por medianos (entre 20 y $50 \mathrm{ha}$ ) y grandes propietarios (50 ha o más), excluyendo a la mayoría de los beneficiarios indirectos de los cuerpos de agua y canales del distrito de riego, particularmente, las poblaciones que usaban el distrito como fuente de agua para el hogar. Este modelo de cesión de responsabilidades estatales para la adecuación de las tierras de campesinos medianos y pequeños propietarios fue reflejo de un fenómeno global relacionado con el neoliberalismo y el fracaso de las políticas proteccionistas de las décadas anteriores. La transferencia del manejo del distrito también fue un proceso de privatización y control del acceso al agua en la región de Montes de María, dado que afectó a los campesinos sin tierra que no tenían voz ni voto en la administración de la Asociación de Usuarios.

En el marco de esta dinámica de exclusión de pequeños campesinos de la administración del agua y de quiebra del arroz, en 1998 llegaron al municipio los primeros cultivos de palma de aceite apoyados por el entonces ministro de Agricultura, Carlos Murgas Guerrero, conocido actualmente como el "Zar de la

16 El Instituto Colombiano de Adecuación de Tierras (INAT) fue una entidad del Estado encargada de las obras de riego y adecuación de varios tipos de infraestructura para el campo. Esta institución fue liquidada por medio del Decreto 1291 del 2003 y fue creada por la Ley 99 de 1993. Antes de 1993 la institución que hacía las veces del INAT fue el Instituto Colombiano de Hidrología, Meteorología y Adecuación de Tierras (Himat), una institución que había sido clave para la materialización de la Ley de Reforma Agraria de 1961. 
Palma”17 (Menco 2011). La experiencia con el arroz había dejado en los habitantes locales desconfianza frente a los proyectos de desarrollo liderados por el Gobierno nacional, de allí la baja aceptación que tuvo la palma en un principio. Como mecanismo de cooptación, el Gobierno ofreció créditos asociativos, subsidios y respaldo de créditos previamente adquiridos, a través del Fondo Agropecuario de Garantías, una entidad estatal para el fomento del agro (Aguilera 2002). Al tiempo que se ofrecía el dinero para la palma, se cerraba el crédito para otros cultivos y se presionaba por el pago de las deudas adquiridas previamente con el arroz. Bajo dichas condiciones, algunos campesinos beneficiarios de la reforma se acogieron al nuevo proyecto productivo basado en la palma, mediante la figura de alianzas productivas ${ }^{18}$. La formalización de títulos de propiedad requerida para el establecimiento de las alianzas, por parte de campesinos locales, y la adquisición y adecuación de una planta extractora, por parte del grupo empresarial Oleoflores, favorecieron las condiciones para que los cultivos de palma fueran los principales beneficiados del riego. El incremento en los predios sembrados de palma en el área de influencia del distrito, junto con el deterioro físico y administrativo de este, abonaron el terreno para la creación de una nueva asociación nominada Usomarialabaja, en la que tenían participación el grupo empresarial y los ahora campesinos productores de palma. Si bien Oleoflores no era el propietario de la mayoría de los predios, sí era el dueño de toda la producción; de allí que concediera la presidencia de la Asamblea General de Usuarios a Carlos Murgas hasta el 2017. Desde la perspectiva institucional, este proceso de control de los palmeros sobre el distrito de riego se ve de la siguiente manera:

La cartera se mejora un poco cuando llega el programa de la palma, entonces la palma asume la figura de las alianzas productivas en donde encontramos un ente integrador que es la promotora - planta extractora- Hacienda Las Flores. La promotora los agremia a través de asociaciones de palmicultores [...] al estar en una asociación, la promotora asume inmediatamente todos los costos y gastos [en] que ellos incurren. Ellos pagan el uso de todos los predios que tienen palma [...] nos hacen un desembolso a nosotros como recaudadores. En ese sentido, nosotros recuperamos el $100 \%$ de la cartera que se le da al grupo de palmicultores

17 Para el 2017, Carlos Murgas figura como el principal accionista del grupo empresarial Oleoflores, empresa que monopoliza la industrialización del aceite de palma en el país.

Las alianzas productivas plantean la unión entre campesinos, en calidad de productores y conglomerados empresariales que fungen como socios estratégicos. La unión estipula la siembra mínima de 10 ha en palma, cuyos insumos (semillas, fertilizantes y herbicidas) son suministrados por el socio estratégico. La implementación de la figura requiere la formalización de los títulos de propiedad y el pago de insumos por parte de los campesinos productores. Una vez se alcanza la primera cosecha, esta debe ser vendida al conglomerado (Ministerio de Agricultura y Desarrollo Rural 2013). 
[...] hemos mejorado un poco las finanzas, y que de pronto a veces nosotros nos atrevemos a decir que con la palma, con esos ingresos se hace posible la dinamización de la empresa, que no se paralice por falta de recursos. (Eduardo Castaño, gerente de Usomarialabaja, junio del 2015)

La consolidación de la producción palmera en el municipio tuvo como agravante la presencia paramilitar del bloque Héroes de los Montes de María, que tenía vínculos estrechos con estamentos políticos y grupos económicos de todo nivel (“¿Cómo se fraguó la tragedia de los Montes de María?” 2010). Su operación en la región se registra desde mediados de la década de los noventa, momento de recrudecimiento de la violencia expresada en masacres, violaciones, desapariciones, desplazamiento y abandono de tierras por parte de pequeños campesinos. Las cifras indican 56 masacres entre 1997 y el 2004; 220 muertes de civiles, de los cuales el $80 \%$ fueron víctimas del paramilitarismo; 200.000 casos de desplazamiento forzado y el despojo de 80.000 ha de tierra entre 1997 y el 2007 (De los Ríos, Becerra y Oyaga 2012, 32). El acaparamiento se efectuó a través del “clientelismo armado" (Grupo de Memoria Histórica 2010) que favoreció el incremento de las áreas sembradas con palma en el municipio, que llegaron a 6.000 ha en el 2005 (PNUD 2010). El aumento del cultivo de palma en las zonas bajas y medias, junto con la privatización de la administración del distrito de riego, dieron paso a dinámicas de despojo de otros recursos, como la captación y manejo de estos a partir de procedimientos legales y políticos por parte de empresarios y terratenientes (Borras, Franco y Wang 2013).

Además de la violencia paramilitar, que las narrativas oficiales declararon como terminada con la desmovilización de las Autodefensas Unidas de Colombia (AUC) en el 2005, los habitantes locales tuvieron que sortear otro tipo de violencias asociadas al despojo de recursos como el agua (Ojeda et al. 2015). El acaparamiento del agua del distrito por empresarios palmeros redundó en el cerramiento de pozos comunales y jagüeyes mediante cercas y vigilancia privada instaladas por grupos paramilitares, así como la contaminación de las fuentes hídricas a causa del vertimiento de agroquímicos utilizados en la industria de la palma. En ese sentido, las denuncias de habitantes y organizaciones se centran en mostrar cómo la contaminación afecta directamente los usos tradicionales del agua y reflejan de qué manera la instalación de cercas alrededor de los cuerpos de agua incide en el acceso desigual sobre la cantidad y la calidad del líquido para las actividades cotidianas (Isch 2010). Las pocas alternativas que encuentran las comunidades para suplir sus necesidades de agua también se ven atravesadas por lógicas de género que afectan de manera diferencial a hombres y mujeres. Con esto nos referimos a que son las mujeres quienes se encargan 
de su aprovisionamiento para todas las tareas del hogar. Puesto que el agua del distrito se encuentra contaminada, son ellas quienes más se exponen a contraer enfermedades por las actividades que realizan, como el lavado de ropa o de la loza. De igual manera, cuando acuden a los pozos y jagüeyes en busca de agua menos contaminada, para consumir o cocinar, se ven expuestas a constantes discusiones con los vigilantes que rondan los predios donde se encuentra el líquido.

En términos generales, los hechos presentados reflejan un ciclo de privatización/acaparamiento/despojo de agua y de tierras en el que la infraestructura agrícola desempeña un papel activo, en la medida en que se convierte en la única fuente de agua de las poblaciones locales y parte de su territorio. En esta lógica, desde su construcción, el distrito medió en las formas de acceso al agua y modificó el paisaje, apuntalando la producción y expansión de monocultivos que requerían gran cantidad de este recurso y concentraban la tierra. Su construcción abonó el terreno para un proceso de apropiación y resignificación local de la infraestructura por parte de las poblaciones locales, posicionando el agua como columna vertebral de su territorio, tema del siguiente apartado.

\title{
Agua para regar la tierra y cultivar la vida
}

\begin{abstract}
Nosotros teníamos unos ojos de agua que eran todo el año, los que vivían allá cogían agua allá, los que vivíamos acá cogíamos agua acá y no teníamos que hacer pozos. En estos momentos, usted va a esa zanja y hay agua corriendo, todo el año agua corriendo. Llegando Semana Santa, usted llevaba agua en jarras, era agua cristal... hoy no, en esos tiempos era calidad de agua, hoy corre con grasa. (Juan Carlos, Marialabaja, junio del 2014)
\end{abstract}

Como se vio en los apartados anteriores, grandes y medianos dueños de tierras, campesinos y pescadores han usado el distrito de riego de Marialabaja de formas muy diferentes a lo largo de su historia. Para las poblaciones locales, el distrito de riego significa una posibilidad de acceder al agua, tanto para sus actividades productivas, como para la vida cotidiana. Lavar la loza y la ropa en compañía de las vecinas, llenar cubetas de hielo, cocinar, limpiar los patios y regarlos para mitigar el fogaje ${ }^{19}$ son solo algunos de los usos que se le da al agua del distrito de riego en los caseríos que lo rodean. El agua que contiene es un eje articulador 
de las formas de regar la tierra y cultivar la vida de las poblaciones campesinas, es decir, se convierte en el centro de los debates por la defensa del territorio. De allí que los procesos de resignificación de la infraestructura y del agua, que son formas locales de reproducir la vida, constituyan la base de los procesos de movilización social frente a los ciclos de privatización/acaparamiento/despojo descritos.

La violencia paramilitar, que tuvo su apogeo entre 1999 y el 2005, desplazó a cientos de personas de sus tierras. Cinco años después parte de estos hombres y mujeres campesinos retornaron a sus hogares y comenzaron a construir organizaciones veredales, a partir de las cuales fuera posible retomar las actividades productivas y políticas que tenían antes de la violencia paramilitar y el cultivo de palma de aceite. Este retorno se dio con el apoyo y el acompañamiento de cooperación internacional, los Planes Nacionales de Consolidación ${ }^{20}$ y la construcción de Laboratorios de $\mathrm{Paz}^{21}$ (Podec 2011). El retorno comenzó después de la desmovilización de los grupos paramilitares, sin que esto significara el fin de la violencia en la región, pues regresaban al territorio sin ningún tipo de garantías de seguridad por parte del Estado.

Este regreso vino acompañado de una serie de estrategias de resistencia y de defensa del agua en el marco de la construcción de un territorio de paz. Las principales estrategias, que también son formas de resignificación del territorio y de la naturaleza, estuvieron basadas en: 1) la conformación de organizaciones sociales y la propuesta de un ordenamiento territorial regional, que tiene como eje la economía campesina y las prácticas de uso de agua relativas a esta actividad; 2) la reconstrucción de prácticas cotidianas de manejo del agua tanto para la siembra y la pesca como para el acceso al agua potable. Estas estrategias trascienden los reclamos por la tierra y reivindican prácticas, conocimientos y relaciones específicas entre los humanos y el entorno, como formas de habitar el espacio.

En este apartado argumentamos que el agua se integra a las luchas por el territorio, de tal forma que se convierte en parte fundamental de la percepción del espacio y de los ejercicios locales de resignificación de la naturaleza. Se trata de la manera como el agua es integrada al discurso y las luchas socioterritoriales locales mediante tres mecanismos que se traducen en prácticas cotidianas: 1) defensa

20 Planes militares emitidos por primera vez en el 2007 por la Presidencia de la República, con el objetivo de aumentar la presencia militar en ciertas zonas priorizadas para "recuperar socialmente el territorio", a partir del trabajo conjunto entre las fuerzas militares y policiales y el área social, de justicia y desarrollo económico.

21 Los Laboratorios de Paz son una herramienta de cooperación técnica y financiera de la Unión Europea con Colombia, enfocada en el fortalecimiento de una cultura de paz basada en el diálogo, los derechos humanos, el derecho internacional humanitario, el mejoramiento de las condiciones socioeconómicas, el fortalecimiento institucional y la participación ciudadana para el pleno disfrute de una vida digna. 
de lo público y discusiones acerca de la propiedad del agua e impulso de procesos de colectivización de la propiedad y la producción; 2) integración de conocimientos ambientales en términos de sostenibilidad del territorio; 3) integración del ámbito cotidiano y privado a las luchas comunitarias, teniendo como referencia la memoria como estrategia de resistencia.

La historia de las organizaciones sociales a escala regional se remonta a la década de los setenta con la ANUC. Su influencia propició la conformación de comités veredales encaminados a la defensa de la tierra, que fungieron como las primeras formas de organización y como la base organizativa de las juntas de acción comunal ${ }^{22}$. El trabajo y la articulación regional por medio de la ANUC generaron redes locales basadas en la estructura familiar y relaciones de amistad, que integraron la organización hasta la década de los ochenta. Para el 2017, en Montes de María existían varios tipos de organizaciones con diferentes escalas de incidencia y acción política, todas ellas herederas de la ANUC. Encontramos a las organizaciones que actúan desde sus veredas y se componen de vecinos y amigos; otras de mayor incidencia que reúnen estas organizaciones más pequeñas y actúan como articuladores de propuestas locales, y otras que cumplen el papel de acompañamiento y gestión, también de escala regional.

Desde el inicio del debate por la defensa del agua, que surgió asociado a los problemas de escasez y contaminación, todas las organizaciones sociales plantearon la necesidad de reconocer los cuerpos de agua del distrito de riego de Marialabaja como patrimonio público; es decir, como inalienable, imprescriptible e inembargable. Al respecto, la Corporación Desarrollo Solidario ${ }^{23}$ (CDS) menciona:

Un paisaje que combina bosques, montañas y agua: es el Distrito de Riego de Marialabaja. Es en realidad un patrimonio público de las comunidades de San Jacinto, Marialabaja, Carmen de Bolívar y en general los Montes de María, así como de las ciudadanías cartageneras y bolivarenses. (“El Distrito de Riego de Marialabaja ¿Patrimonio público?” 2015)

Aunque este tipo de instancias no gubernamentales fungen como apoyo a las iniciativas de defensa del agua, habitantes y organizaciones locales reclaman la propiedad de esta a partir de la resignificación de los cuerpos de agua como un bien común; como la práctica de un trabajo-para-todos (Gutiérrez y Salazar 2015). Es decir, la funcionalidad del distrito de riego administrado por Usomarialabaja

22 Según dicen los campesinos, nunca ejercieron actividades organizativas que impactaran en la zona.

23 La Corporación Desarrollo Solidario (CDS) es una ONG local que acompaña parte de las organizaciones sociales de Marialabaja y otros municipios de la región desde 1992. 
está inserta en las formas campesinas de pensar y vivir el territorio, de reproducir la vida. De allí se entiende que el debate sobre el acceso al agua tenga como punto de partida un reclamo de los derechos de propiedad, entendidos más allá de la propiedad física y legal (Ribbot y Peluso 2003).

La integración del distrito de riego como un bien común va de la mano de la propuesta de delimitación del territorio, llamada zona intercultural de protección territorial $^{24}$. Esta zona integra las demandas relacionadas con el acceso al agua del distrito de la región, desde dos puntos de vista: la necesidad y la articulación con las economías campesinas y la protección frente a la contaminación ocasionada por los fertilizantes y pesticidas usados en el cultivo de palma. Si bien esta propuesta está acompañada por la cooperación internacional y organizaciones que cobijan toda la región de Montes de María, uno de los principales objetivos es incluir el distrito de riego y los cuerpos de agua como columna vertebral de la región. La zona intercultural de protección territorial parte de una lectura de las formas de despojo del agua ejercidas por el cultivo de palma de aceite y responde al contexto con propuestas concretas de cuidado y restauración de las fuentes de agua. En términos generales, estas formas de reivindicación son parte de un proceso de resignificación de la naturaleza que alimenta la movilización por la defensa del agua como un bien común.

En el marco del despojo, la contaminación y el control del agua se perfilan como las preocupaciones más acuciantes para los habitantes locales. Sus demandas contemplan formas de conservación de cuerpos de agua, relacionadas con la reforestación del bosque seco tropical por medio de la siembra de "árboles que llaman agua” (varios, comunicación personal, julio del 2016), como el caracolí, y la aplicación de conocimientos locales para evitar su desecamiento y la pérdida de especies nativas de peces, como el currulá, el moncholo, el macaco, la dorada y el bocachico. Estas formas de control y de recuperación de espacios de agua

24 La zona intercultural de protección territorial nace como una iniciativa local frente a la delimitación de las zonas de reserva campesina propuestas por el Gobierno nacional en el 2010. Esta iniciativa integra la necesidad de construir una zona de economías campesinas para la región, pero incluye la integración de pueblos indígenas y afrodescendientes en la delimitación. Para su implementación se creó la Mesa de Interlocución de los Montes de María (MIC) en el 2011. Desde su creación hasta la fecha, se ha avanzado en la caracterización de la región, en cabeza del Centro de Estudios Interculturales de la Pontificia Universidad Javeriana de Cali y algunos encuentros con cabildos indígenas y consejos comunitarios. $\mathrm{Ni}$ la zona de reserva campesina propuesta por el Gobierno ni la zona intercultural de protección cuentan con declaratoria oficial. La liquidación de Incoder ha retrasado aún más una respuesta oficial. 
tienen que ver con conocimientos ambientales locales ${ }^{25}$, tal como lo muestra el siguiente fragmento:

Finalmente, aclaramos que la recuperación del sistema cenagoso no es un beneficio exclusivo para los pescadores de la región. Es la oportunidad de rescatar un nicho de biodiversidad, que pueda contrarrestar los efectos actuales del cambio climático y calentamiento global. Significa también contribuir al posicionamiento de una actividad de vieja data a la cual no se le ha dado mayor reconocimiento en el país y es la posibilidad de que la región sobresalga en el ámbito nacional al apoyar la pesca artesanal. (Repisnobol, CDS y AIDA 2014)

La integración del ámbito cotidiano y privado a las luchas comunitarias por la defensa del agua y del territorio pasa por reconocer los mecanismos de captación de agua, incluida la de lluvia, como pozos, jagüeyes, ojos de agua, llaves caseras, embalses y los canales, así como el uso que se les da. El destino de dichas aguas depende de su origen: el agua para cocinar y tomar se recoge en los pozos comunales, ojos de agua, jagüeyes y el tanque de almacenamiento que se surte de agua lluvia en la temporada de invierno. El agua del distrito y de las llaves - que tiene el mismo origen- se destina para los oficios de la casa y el mantenimiento de patios y parcelas. En épocas de verano casi todas las fuentes diferentes al distrito se secan, de modo que los embalses suplen todas las necesidades cotidianas. Es importante mencionar que, como consecuencia de la contaminación, tanto hombres como mujeres han denunciado el aumento de enfermedades gastrointestinales y dermatitis en la población general, e infecciones vaginales en el caso de las mujeres.

Las actividades cotidianas que tienen que ver con el uso del agua en el hogar y con el uso productivo y comunitario responden entonces a procesos de resignificación de la infraestructura. Las formas de moverse entre los espacios de producción comunitarios ${ }^{26}$, el uso del agua desde el hogar hasta la producción agrícola, las estrategias de defensa del agua potable y los sistemas de acueductos

"Los conocimientos ambientales locales se constituyen en un cuerpo acumulativo de conocimientos, prácticas y creencias que evolucionan por procesos adaptativos y son transmitidos de generación en generación a través de la cultura. Estos conocimientos hablan de la relación de los seres vivos (incluyendo humanos) entre sí y con su entorno. Tales conocimientos abarcan el conocimiento local de los recursos naturales disponibles, como alimentos, medicinas, madera y leña, y no solo integran ideas sobre dónde están ubicados sino también la manera de cosechar, preparar y evitar la sobreexplotación" (Horowitz 2015, traducción propia). Una es la instalación de jaulas comunitarias para la cría de peces y la otra son las parcelas colectivas. En los dos casos, un grupo de personas se hace cargo de la producción y resulta beneficiado de esta. 
y saneamiento básico gestionados de forma comunal, así como la construcción de sistemas de riego locales que utilizan el distrito, son algunas de las formas como mujeres y hombres apropian y le dan sentido al agua en la región. Es decir, cada vez que una familia instala una tubería subterránea que conecta con alguna represa del distrito del riego, está resignificando el uso del agua, y por lo tanto el sistema general de riego. El agua deja de ser exclusiva de la producción de aceite de palma y se convierte en un bien común que permite reproducir la vida local. Si bien esto se da en un contexto de despojo, las estrategias de la gente van de la mano de la construcción de espacios de esperanza, del diseño espaciotemporal de formas locales - utopías dialécticas - que se contraponen a las espacialidades capitalistas (Harvey 2003). Son prácticas cotidianas y de consolidación de organizaciones sociales que incluyen el agua en los debates por la defensa del territorio.

\section{Conclusiones}

Tanto el agua y la infraestructura como las poblaciones locales, las instituciones y los conglomerados empresariales tienen el poder de modificar la geografía y el paisaje, no solo en términos materiales, sino también a partir de los significados que construyen en relación con el agua. Cada actor resignifica el agua dependiendo de las prácticas que permiten la producción de mercancías, en el caso de la palma, o reproducen la vida, en el caso de las comunidades. Estos hechos son importantes para un análisis etnográfico de escenarios donde el agua cobra importancia, permitiendo reconocer las redes enraizadas (Rocheleau 2011) que se construyen a través de prácticas y representaciones sobre la naturaleza, y que tienen efectos materiales en la producción de territorios. Así mismo, la disponibilidad y el control del agua permiten reconocer las tensiones entre los actores y la construcción de territorialidades. Es clave comprender que estudiar el acceso y la distribución de agua es una opción para analizar procesos tanto de despojo como de resignificación y defensa de lo local.

En el caso de Marialabaja, la construcción del distrito de riego rompió y alteró las relaciones con el agua. La infraestructura transformó el espacio por medio de tecnologías de control de cauces, sedimentando espacialmente formas desiguales de acceso al agua, de las que resultan una serie de conflictos socioambientales caracterizados por las luchas locales por el acceso al líquido y el uso de los bienes comunes. El caso concreto es una red enraizada de significados y prácticas que se producen en las relaciones entre los seres humanos y la naturaleza. 
En este artículo consideramos los mecanismos de apropiación del entorno, basados en la delimitación y construcción de subjetividades asociadas al distrito de riego y que son la base fundamental de los procesos de resignificación de este. Un escenario de escasez de agua en medio de la abundancia refleja cómo las geografías sedimentadas (Ojeda et al. 2015) no solo son escenarios de desigualdad, sino que pueden ser espacios transformados a través de la construcción de nuevos espacios y nuevos sentidos de la naturaleza.

Las experiencias asociadas a la economía campesina -producción de alimentos, prácticas agroecológicas, fortalecimiento de redes sociales, entre otras - son claves para reconocer la profunda relación entre la vida productiva cotidiana y el agua, y la reproducción de la vida misma. Al tener el agua como centro del ordenamiento territorial, se pueden reconocer los avances en la lectura integral del paisaje y las posibilidades de sostenibilidad de este espacio a futuro. Si bien la importancia del agua nace de crisis locales, hoy es central en las visiones sobre el territorio campesino y étnico en la región, las cuales provienen de discusiones que se entablan en el día a día y resultan en proyectos de ordenamiento espacial de gran escala.

El distrito de riego de Marialabaja permite reconocer un conflicto socioambiental relacionado con escalas más amplias, como los planes y políticas de desarrollo nacional y con visiones disonantes sobre el desarrollo para la región de Montes de María y para el Caribe en general. El agua se sitúa en el centro de un debate por los derechos sobre el territorio, en la medida en que las organizaciones locales consideran de manera integral el papel del agua en el paisaje y dentro de los límites del territorio campesino. El valor del líquido va más allá de una mirada funcional y se integra a las discusiones sobre la propiedad de un bien común, cuya importancia se ve en las diferentes escalas de la vida cotidiana y en las formas de producción ancladas a las economías campesinas.

Mediante estas reflexiones queremos aportar a la comprensión del despojo como parte de un ciclo que, en el caso de Marialabaja, resultó en la construcción, delimitación y definición de espacios de esperanza, siempre en disputa con las lógicas de desarrollo impuestas. Desde nuestra perspectiva, reconocer el agua como un elemento dinámico y construido social, política y económicamente presenta un reto, tanto para las organizaciones sociales como para la academia, que muchas veces ha privilegiado a la tierra sin tener en cuenta la importancia del agua para la comprensión del espacio y la defensa de los territorios rurales. Sin duda, el análisis de las estrategias locales de resignificación de una obra de infraestructura es una propuesta a futuro para reconocer los ciclos completos de las políticas de despojo asociadas al desarrollo, que no se reducen a la 
victimización y exclusión sino que son reconfiguradas mediante acciones que trasforman realidades desde lo cotidiano.

\section{Referencias}

“Agua bendita”. Semana. 2016. http://especiales.semana.com/agua-bendita/introduccion.html.

Aguilera, María. 2002. "Palma africana en la costa caribe: un semillero de empresas solidarias”. Documento de Trabajo sobre Economía Regional 30. Cartagena: Banco de la República. http://www.banrep.gov.co/sites/default/files/publicaciones/archivos/DTSER30-PalmaAfricana.pdf.

—. 2013. “Montes de María: una subregión de economía campesina y empresarial”. Documento de Trabajo sobre Economía Regional 195. Cartagena: Banco de la República. http://www. banrep.gov.co/docum/Lectura_finanzas/pdf/dtser_195.pdf.

Aguirre, Amín, Duván Caro, Catalina Quiroga y Diana Vallejo. 2016. Historia del distrito de riego de Marialabaja: más motivos para decir que el agua es nuestra. Proyecto local de co-investigación. Bogotá: Pontificia Universidad Javeriana. http://passthrough.fw-notify. net/download/747246/http://rutasdelconflicto.com/especiales/acuatenientes/documentos/ riego-archivo2.pdf.

Albán, Álvaro. 2011. "Reforma y contrarreforma agraria en Colombia”. Revista de Economía Institucional 13 (24): 327-356.

Alimonda, Héctor, ed. 2011 La naturaleza colonizada. Ecología política y minería en América Latina. Buenos Aires: Ciccus; Clacso.

Bakker, Karen. 2003. "A Political Ecology of Water Privatization”. Studies in Political Economy 70: 35-58.

-. 2010. "The Limits of Neoliberal Natures: Debating Green Neoliberalism". Progress in $\mathrm{Hu}$ man Geography 34 (6): 715-735.

-. 2012. "Water: Political, Biopolitical, Material”. Social Studies of Science 42 (4): 616-623. http://sss.sagepub.com/content/42/4/616.

-. 2015. "Neoliberalization of Nature”. En The Routledge Handbook of Political Ecology, editado por Tom Perreault, Gavin Bridge y James McCarthy, 446-457. Londres: Routledge Taylor \& Francis Group.

Boelens, Rutgerd, Jaime Hoogesteger, Erik Swyngedouw, Jeroen Vos y Philippus Wester. 2016. "Hydrosocial Territories: A Political Ecology Perspective”. Water International 41 (1): 1-14. DOI: 10.1080/02508060.2016.1134898.

Borras, Saturnino, Jennifer Franco y Chunyu Wang. 2013. "The Challenge of Global Governance of Land Grabbing: Changing International Agricultural Context and Competing Political Views and Strategies”. Globalizations 10 (1): 161-179. https://doi.org/10.1080/14747 731.2013.764152. 
Budds, Jessica. 2010. "Las relaciones sociales de poder y la producción de paisajes hídricos”. En Justicia hídrica: siete ensayos como aportes para articular las luchas, editado por Hildebrando Vélez Galeano, 31-44. Bogotá: Censat Agua Viva; Amigos de la Tierra Colombia.

“Caja Agraria: adiós a otra insignia nacional”. 2007. Portafolio, 5 de marzo. http://www. portafolio.co/economia/finanzas/caja-agraria-adios-insignia-nacional-230350.

Camargo, Alejandro. 2008. "Una tierra bondadosa: progreso y recursos naturales en la región del río San Jorge, siglo XX”. Historia Crítica 37: 170-191.

Carse, Ashley. 2012. "Nature as Infrastructure. Making and Managing the Panama Canal Watershed”. Social Studies of Science 42 (4): 539-563. https://doi.org/10.1177/0306312712440166.

Castree, Noel. 2008. "Neoliberalising Nature: The Logics of Deregulation and Reregulation”. Environment and Planning A: Economy and Space 40 (1): 131-152. https://doi.org/10.1068/ a3999.

Caviedes, Raimundo. 1975. "Empresas comunitarias del Incora: proyecto Bolívar 1”. Tesis de grado, Departamento de Sociología, Universidad Social Católica La Salle, Bogotá.

“Cómo se fraguó la tragedia de los Montes de María?”. 2010. Verdad Abierta. http://www. verdadabierta.com/la-historia/la-historia-de-las-auc/2676-icomo-se-fraguo-la-tragediade-los-montes-de-maria.

Coronado, Sergio y Kristina Dietz. 2013. “Controlando territorios, reestructurando relaciones socioecológicas: la globalización de agrocombustibles y sus efectos locales, el caso de Montes de María en Colombia”. Iberoamericana XIII (49): 93-115.

Cortés, Antonio, Victoria Quintero y José María Valcuende. 2008. "Contemplar o vivir. Símbolos y legitimaciones en un espacio protegido”. En Patrimonialización de la naturaleza. El marco social de las políticas ambientales, coordinado por Oriol Beltrán, José J. Pascual Fernández e Ismael Vaccaro, 65-82. San Sebastián: Ankulegi.

De los Ríos, Edwin, Carmen Andrea Becerra y Fabián Enrique Oyaga. 2012. Montes de María. Entre la consolidación del territorio y el acaparamiento de tierras. Bogotá: ILSA.

Del Cairo, Carlos, Iván Montenegro Perini y Juan Sebastián Vélez. 2014. "Naturalezas, subjetividades y políticas ambientales en el noroccidente amazónico: reflexiones metodológicas para el análisis de conflictos socioambientales”. Boletín de Antropología 29 (48): 13-40.

Departamento Administrativo Nacional de Estadística (DANE). 2005. Censo General 2005. Consultado el 13 de junio del 2016. https://www.dane.gov.co/index.php/estadisticaspor-tema/demografia-y-poblacion/censo-general-2005-1.

Fals, Orlando. 1976. Capitalismo, hacienda y poblamiento: su desarrollo en la costa atlántica. Bogotá: Punta de Lanza.

Fernandes, Bernardo. (2010). “Territorios en disputa: campesinos y agrobusiness”. Land Research Action Network.

García, Paola. 2014. Un desarrollo pasado por agua. Dramas y conflicto en la región del canal del Dique. Bogotá: Universidad de los Andes; Centro Interdisciplinario de Estudios sobre Desarrollo (Cider); Departamento para la Prosperidad Social; Unión Europea.

Göbel, Barbara, Manuel Góngora-Mera y Astrid Ulloa. 2014. "Las interdependencias entre la valorización global de la naturaleza y las desigualdades sociales: abordajes 
multidisciplinarios”. En Desigualdades socioambientales en América Latina, editado por Bárbara Göbel, Manuel Góngora-Mera y Astrid Ulloa, 13-46. Bogotá; Berlín: Universidad Nacional de Colombia (sede Bogotá); Ibero-Amerikanisches Institut.

Grupo de Memoria Histórica. 2010. La tierra en disputa. Memorias del despojo y resistencias campesinas en la costa caribe: 1960-2010. Bogotá: Ediciones Aguilar. http://www.centrodememoriahistorica.gov.co/descargas/informes2010/tierra_conflicto/la_tierra_en_\%20 disputa.pdf.

Gutiérrez, Raquel y Huascar Salazar. 2015. "Reproducción comunitaria de la vida. Pensando la trans-formación social en el presente”. El Apantle, Revista de Estudios Comunitarios 1: $15-50$.

Harvey, David. 2003. Espacios de esperanza. Madrid: Akal.

-. 2005. El nuevo imperialismo: acumulación por desposesión. Buenos Aires: Clacso.

Herrera, Martha. 2002. Ordenar para controlar. Ordenamiento espacial y control político en las llanuras del Caribe y en los Andes centrales neogranadinos, siglo XVIII. Bogotá: Instituto Colombiano de Antropología e Historia; Academia Colombiana de Historia.

Instituto Colombiano de Desarrollo Rural (Incoder). 2008. "Rehabilitación y/o complementación del distrito de riego en gran escala Marialabaja - departamento de Bolívar”. https://colombialicita.com/licitacion/112161.

-. 2012. "Plan de Desarrollo Sostenible para Zona de Reserva Campesina en Montes de María. Zona 1”. Consultado el 13 de junio del 2018. https://issuu.com/centrodedocumentacionanzorc/docs/zrcma_informe_final_1_diagnostico.

-. 2015. "Presentación general distrito de riego de Marialabaja". Consultado el 13 de junio del 2018. http://www.Incoder.gov.co/documentos/A\%C3\%910_2015/Adecuaci\%C3\%B3n\% 20de\%20Tierras/Presentaciones\%20Gran\%20Escala\%20Usuarios/PRESENTACI\%C3\%93 N\% 20DISTRITO\%20MARIA\%20LA\%20BAJA.pdf.

Instituto Colombiano de la Reforma Agraria (Incora). 1968. Serie de divulgación Proyectos 1. Bolívar 1. Mahates, Marialabaja, Arjona: Adecuación de 25.000 hectáreas en beneficio de 1.300 familias. Bogotá: Incora.

Isch, Edgar. 2010. “La contaminación del agua como proceso de acumulación”. En Justicia hídrica: 7 ensayos como aportes para articular las luchas, 107-120. Bogotá: Censat Agua Viva; Amigos de la Tierra Colombia.

Lefebvre, Henri. (1974) 2013. La producción del espacio. Madrid: Capitán Swing.

Ley 135 de 1961. "Sobre reforma social agraria”. Diario Oficial de Colombia. Año XCVIII, n. ${ }^{\circ}$ 30.691. 20 de diciembre de 1961.

Linton, Jamie y Jessica Budds. 2013. “The Hydrosocial Cycle: Defining and Mobilizing a Relational-dialectical Approach to Water”. Geoforum 57: 170-180. http://dx.doi.org/10.1016/j. geoforum.2013.10.008.

López, Diana Marcela. 2013. Flows of Water, Flows of Capital: Neoliberalization and Inequality in Medellín's Urban Waterscape. desiguALdades.net. Working Paper Series n. ${ }^{\circ}$ 38. Berlín: desiguALdades.net Research Network on Interdependent Inequalities in Latin America. 
Martínez, Aura Isabel. 2006. "Apertura económica en Colombia y el sector externo. 1990-2004”. Apuntes del Cenes 26 (41): 77-98. https://dialnet.unirioja.es/descarga/articulo/4829182.pdf.

Mehta, Lyla. 2007. "Whose Scarcity? Whose Property? The Case of Water in Western India". Land Use Policy 24 (4): 654-663.

Menco Rivera, Daniel. 2011. "Palma aceitera y la seguridad alimentaria en María La Baja, Montes de María. 2000-2008”. En Observatorio de la Economía Latinoamericana 157: 1-23. http://www.eumed.net/cursecon/ecolat/co/.

Mesa de Interlocución y Concertación de los Montes de María. 2017. "En busca de la permanencia digna en el territorio”. Revista Economía \& Región 11 (2): 339-359. https://econpapers.repec.org/article/col000411/016079.htm.

Molano, Alfredo. 2011. “Montes de María”. El Espectador, 21 de mayo. http://www.elespectador.com/noticias/nacional/montes-de-maria-articulo-271613.

Ojeda, Diana. 2016. "Los paisajes del despojo: propuestas para un análisis desde las reconfiguraciones socioespaciales”. Revista Colombiana de Antropología 52 (2): 19-43. https://doi. org/10.22380/2539472X.27.

Ojeda, Diana, Jennifer Petzl, Catalina Quiroga, Ana Catalina Rodríguez y Juan Guillermo Rojas. 2015. "Paisajes del despojo cotidiano: acaparamiento de tierra y agua en Montes de María, Colombia”. Revista de Ciencias Sociales 54: 107-119. DOI: http://dx.doi. org/10.7440/res54.2015.08.

OPDS Montes de María. 2015. “El distrito de riego de Marialabaja: ¿patrimonio público?”. 26 de marzo del 2015. Consultado el 13 de junio del 2016. http://montesdemariamitierramidentidad.blogspot.com/2015/05/editorial-el-distrito-de-riego-de.html.

Pérez, Jesús María. 2010. Luchas campesinas y reforma agraria. Memorias de un dirigente de la ANUC en la costa caribe. Bogotá: Punto Aparte Editores.

Perrault, Thomas. 2014. "What Kind of Governance for What Kind of Equity? Towards a Theorization of Justice in Water Governance”. Water International 39 (2): 233-245. https:// doi.org/10.1080/02508060.2014.886843.

Plataforma de Organizaciones de Desarrollo Europeas en Colombia (Podec). 2011. "Análisis del plan de consolidación de Montes de María: una mirada desde el desarrollo, la democracia, los derechos humanos y la cooperación internacional”. Boletín n. ${ }^{\circ}$ 6. http:// www.indepaz.org.co/wp-content/uploads/2011/05/599_Podec-6.pdf.

Programa de las Naciones Unidas para el Desarrollo (PNUD). 2010. Los Montes de María: análisis de la conflictividad. http://www.undp.org/content/dam/undp/documents/projects/ COL/00058220/Analisis\%20conflcitividad\%20Montes\%20de\%20Maria\%20PDF.pdf.

Prudham, Scott. 2004. "Poisoning the Well: Neoliberalism and the Contamination of Municipal Water in Walkerton, Ontario”. Geoforum 35: 343-359.

Quiroga, Catalina. 2016. “'Ya perdimos la tierra, ahora tenemos que luchar por el agua': agua y poder en los Montes de María, municipio de Marialabaja, Colombia”. Tesis de Maestría en Geografía, Universidad de los Andes, Bogotá. 
Repisnobol, CDS y AIDA. 2014. "Problemáticas y potencialidades de la pesca y piscicultura en el norte de Bolívar. Mahates, Bolívar”. Documento presentado en el Foro de Pesca y Piscicultura del Norte del Bolívar, 5 de abril, Mahates, Bolívar.

Ribott, Jesse C. y Nancy Lee Peluso. 2003. “A Theory of Access”. Rural Sociology 68 (2): 153-181. https://doi.org/10.1111/j. 549-0831.2003.tb00133.

Rocheleau, Dianne. 2011. "Rooted Networks, Webs of Relation, and the Power of Situated Science: Bringing the Models Back Down to Earth in Zambrana”. En Knowing Nature: Conversations at the Intersection of Political Ecology and Science Studies, editado por Paul Nadasdy, Mara J. Goldman y Matthew D. Turner, 209-226. Chicago: University of Chicago Press.

"Se hundió proyecto de ley que convertía el agua en derecho fundamental". Semana, 7 de diciembre. http://sostenibilidad.semana.com/medio-ambiente/articulo/agua-como-dere cho-se-hundio-en-el-congreso/36635.

Sultana, Farhana. 2011. "Suffering for Water, Suffering from Water: Emotional Geographies of Resource Access, Control and Conflict”. Geoforum 42 (2): 163-172. https://doi. org/10.1016/j.geoforum.2010.12.002.

Swyngedouw, Erik. 1999. "Modernity and Hybridity: Nature, Regeneracionism, and the Production of the Spanish Waterscape, 1890-1930". Annals of the Association of American Geographers 89 (3): 443-465.

Vallejo, Diana. 2016. “'Estamos viviendo de milagro’: paisajes desiguales de acceso al agua en el Distrito de Riego de Marialabaja-Bolívar”. Tesis de pregrado, Departamento de Antropología, Pontificia Universidad Javeriana, Bogotá.

Van Ausdal, Shawn. 2009. "Potreros, ganancias y poder. Una historia ambiental de la ganadería en Colombia, 1850-1950”. Historia Crítica 126-149. https://doi.org/10.7440/histcrit39E.2009.07.

Vélez-Torres, Irene. 2012. "Water Grabbing in the Cauca Basin: The Capitalist Exploitation of Water and Dispossession of Afrodescendant Communities”. Water Alternatives 5 (2): 421-449.

Vermillion, Douglas y Carlos Garcés-Restrepo. 1999. Impactos del actual programa de transferencia del manejo de la irrigación en Colombia. Informe de investigación 25. Colombo, Sri Lanka: Instituto Internacional de Manejo del Agua. 